\title{
Association between aortic calcification and the presence of kidney stones: calcium oxalate calculi in focus
}

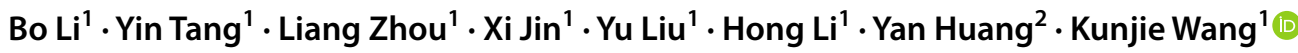

Received: 9 May 2021 / Accepted: 11 November 2021 / Published online: 30 November 2021

(C) The Author(s) 2021

\begin{abstract}
Purpose The current research is aimed at analyzing the relationship between kidney stone (KS) and abdominal aortic calcification (AAC) and the relationship between KS components and AAC.

Methods This is a retrospective, case-control study. Kidney stone formers (KSFs) were treated at the Department of Urology, West China Hospital, Sichuan University for urological calculus disease from January 2014 to January 2020. Matched non-stone formers (non-SFs) were drawn from the same hospital for routine health examination from January 2018 to February 2019. Research-related information was collected and reviewed retrospectively from the hospital's computerized records. AAC were evaluated using available results of computed tomography imaging and abdominal vascular ultrasound. The relationships of AAC between KSFs and non-SFs were compared. The composition of renal calculi was analyzed by Fourier-transform infrared spectrophotometer. KSFs were divided into AAC groups and non-AAC based on AAC. The relationship of the composition of renal calculi between AAC and non-AAC were compared. The independent-sample $t$ test, the chi-squared test and binary logistics regression were performed.

Results Altogether, 4516 people were included, with 1027 KSFs and 3489 non-SFs. There were no significant differences in the laboratory parameters between KSFs and non-SFs. The association between the presence of AAC and KS was significant in multivariable model 2 [adjusting hypertension, diabetes mellitus, fasting blood glucose, uric acid, serum triglyceride (TG), serum calcium, and urine $\mathrm{pH}$ ] (OR 5.756, 95\% CI 4.616-7.177, $p<0.001$ ). The result of KSFs showed that calcium oxalate calculi $(\mathrm{CaOx})$ was significantly associated with AAC in multivariable model 3 (adjusting age, hypertension, diabetes mellitus, drinking history, smoking history, and TG) (OR 1.351, 95\% CI 1.002-1.822, $p=0.048$ ).

Conclusions The current study pioneered the revelation of the relationship between $\mathrm{CaOx}$ and AAC. Through an elimination of the confounding factors, the study demonstrated that KS and AAC were connected.
\end{abstract}

Keywords Nephrolithiasis $\cdot$ Aortic calcification $\cdot$ Calcium oxalate calculi $\cdot$ Screened population

Bo Li, Yin Tang contributed equally to this work.

Yan Huang
huangyanhy513@163.com
Kunjie Wang
wangkj@ scu.edu.cn
Bo Li
260421592@qq.com
Yin Tang
mdtangyin@126.com
Liang Zhou
694098320@qq.com
Xi Jin
10275681@qq.com

Yu Liu

1872150596@qq.com

Hong Li

lihonghxhx@scu.edu.cn

1 Department of Urology, Institute of Urology, Laboratory of Reconstructive Urology, West China Hospital, Sichuan University, Chengdu, China

2 Health Management Center, West China Hospital, Sichuan University, Guoxuexiang 37, Chengdu 610041, China 


\section{Introduction}

Nephrolithiasis, with a high recurrence rate of more than $50 \%$ within 10 years [1], is a problem faced by many, with a prevalence of about $10 \%$ in male and $6 \%$ in female [2]. The diagnosis of kidney stones is generally relatively simple, according to the patient's symptoms, physical examination and auxiliary examinations can be clear. Abdominal CT has become an increasingly popular choice in the diagnosis of urinary calculi, as well as providing other imaging data. Patients with urolithiasis diagnosed through non-contrast CT imaging has more than tripled in the emergency medical unit of the United States, rising to 71\% [3]. The American Urological Association's (AUA) and the European Urological Association's (EUA) guidelines on urolithiasis strongly recommend $\mathrm{CT}$ imaging before surgical intervention for nephrolithiasis [4, 5].

At the same time, abdominal CT is an ideal tool to evaluate abdominal aortic calcification (AAC). In recent years, epidemiologic study have provided evidence for an association between nephrolithiasis and cardiovascular disease [6]. When using CT colonography to assess the condition of the colon, the condition of AAC is introduced to assess the risk of any coronary arterial disease [7]. The increased incidence of cardiovascular disease in kidney stone formers (KSFs) is of great interest, although the underlying mechanisms are not well understood and are mainly being explored.

Both KS and AAC are easy to evaluate. In the case of kidney stone evaluation, performing abdominal CT imaging is an efficient technique. Nonetheless, no studies have been done on the correlation between AAC and KS. The study was based on a hypothesis that there is a relationship between $\mathrm{KS}$ and AAC. In specific, AAC leads to a higher probability of KS occurrence, and the two may have common pathogenesis.

We retrospectively collected the conditional information of abdominal aorta in patients with KSFs and non-SFs, and the composition information of stones in patients with renal calculi. The purpose of the present research is to analyze the relationship between nephrolithiasis and AAC and the relationship between $\mathrm{KS}$ components and $\mathrm{AAC}$, followed by a discussion on whether AAC can predict the occurrence of stones.

\section{Methods}

\section{Participants}

\section{Kidney stone formers and non-stone formers}

This is a retrospective, case-control study. KSFs were treated at the Department of Urology, West China Hospital, Sichuan University for urological calculus disease from January 2014 to January 2020. Matched non-SFs were drawn from the same hospital for routine health examination from January 2018 to February 2019. Kidney stones were diagnosed by professional physician with (non-contrast or contrast) abdominal CT, kidney-ureter-bladder X-ray photography (KUB), or urinary ultrasound.

Demographic and clinical variables of both KSFs and non-SFs include general items (height, weight), laboratory examination (complete blood cell, basic chemistry, blood coagulation, thyroid function, stool/urine analyses), abdominal CT, abdominal aortal ultrasonography, kidney-ureter-bladder X-ray photography (KUB), or urinary ultrasound, etc. KSFs undergone stone composition analysis were included. Non-SFs were unable to evaluate aortic calcification were excluded, and were diagnosed with urinary calculi or underwent urolithiasis-related operations were also excluded. Patients with hyperparathyroidism, renal tubular acidosis, and hereditary urinary lithiasis were excluded. The screening process of patients with KSFs and non-SFs is presented in Figs. 1 and 2. The relationships of AAC between KSFs and non-SFs were compared.

\section{$A A C$ group and non-AAC group}

KSFs were divided into AAC group and non-AAC group based on AAC, shown in Fig. 1. The relationship of the composition of renal calculi between AAC and non-AAC were compared.

\section{Data collection}

Research-related information was collected and reviewed retrospectively from the hospital's computerized records. Specifically, the following parameters were collected: age, gender, body mass index (BMI), diabetes mellitus, hypertension, smoking history, drinking history, stone size, stone location, and laboratory data: FBG, UA, TG, TC, $\mathrm{Ca}$, and $\mathrm{pH}$. 
Fig. 1 Flowchart of inclusion and exclusion of populations with kidney stones
Fig. 2 Flowchart of inclusion and exclusion of healthy physical examination populations

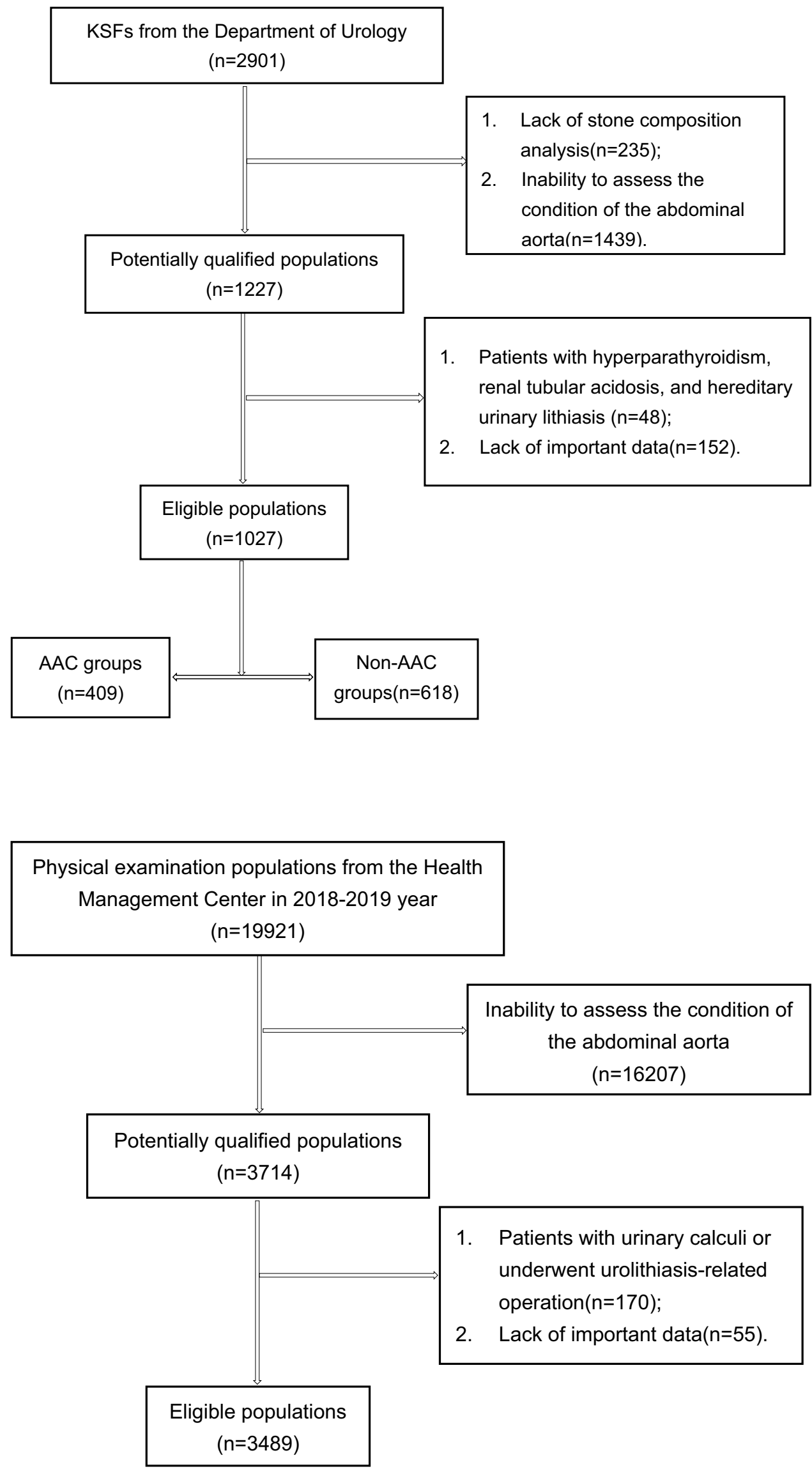




\section{Evaluation of the composition of renal calculi}

The composition of renal calculi was analyzed by Fouriertransform infrared spectrophotometer (Lambda-LIIR.20, Tianjin, China), which were categorized according to EAU guidelines [8]. Evaluated by the main component, stones were divided into $\mathrm{CaOx}$ and carbapatite calculi $(\mathrm{CaP})$. Meanwhile, a stone was treated as a urate stone (UA) if it contained uric acid, sodium urate monohydrate, or ammonium acid urate. Struvite is placed in the group of the same name, "struvite". Cystine $(n=6)$ and drug-induced calculi $(n=1)$ were categorized as "other".

\section{Measurement of abdominal aorta calcification}

AAC were evaluated using available results of abdominal CT imaging and abdominal vascular ultrasound. Ultrasonographic examination of the abdominal aorta is just a supplement. To increase the accuracy of diagnosis of vascular calcification, abdominal vascular ultrasound and abdominal $\mathrm{CT}$ were used for mutual verification of AAC. The measurement range of the abdominal aorta starts at $1 \mathrm{~cm}$ from the starting point of the abdominal aorta and ends at $1 \mathrm{~cm}$ under iliac bifurcation. AAC exists if the aortic wall area is larger than $1 \mathrm{~mm}^{\wedge} 2$, and the density is over 130 Hounsfield unit (HU) using available CT imaging [9]. In an ultrasonographic examination of the abdominal aorta, patients needed to keep the supine position and fast before the examination. The ultrasonic probe was placed at the beginning of the abdominal aorta under the xiphoid process. The longitudinal and transverse sections of the abdominal aorta were observed from the starting point of the abdominal aorta to the iliac bifurcation. Then, the abdominal aorta was magnified routinely during the examination.

\section{Statistical analysis}

In this study, continuous variables were calculated by means \pm standard deviations (SD), whereas categorical variables were measured by counts (percentages). If the continuous variable conforms to the normal distribution, an independent-sample $t$ test was performed. Otherwise, the rank sum test is used. For categorical variables, when $T \geq 5$ and sample size $n \geq 40$, the chi-square test was selected for data analysis. If $1 \leq \mathrm{T}<5$ and $n \geq 40$, the continuity corrected chi-square test was carried out.

Binary logistics regression was utilized to assess the correlation between KS and AAC. Beyond that, multivariable model 1 was set up to adjust age and gender, and multivariable model 2 was designed to adjust age, gender, BMI, diabetes mellitus, hypertension, smoking history, drinking history, FBG, UA, TG, $\mathrm{Ca}$, and urine $\mathrm{pH}$, which studies have confirmed that these factors may be closely related to the occurrence and development of KS [10].

$\mathrm{KS}$ were divided into two groups based on AAC, to evaluate the relationship between AAC and the stone composition. Here, binary logistics regression was performed and multivariable model 3 was framed to adjust age, diabetes mellitus, hypertension, smoking history, drinking history, and TG, which these factors have been shown to be closely related to vascular calcification [11].

This was a two-tailed test and when $p$ value was less than 0.05 , the analysis was considered statistically significant. All statistical analyses were performed with SPSS software (SPSS Inc, Version 22, Chicago, IL, USA). The study protocol was approved by the Biomedical Ethics Committee at West China Hospital, Sichuan University (No. 2015-202).

\section{Results}

In total, 4516 samples were included, including 1027 patients diagnosed with nephrolithiasis, and 3489 non-SFs (i.e., healthy people) as controls. Variables of interest were categorized by the presence or absence of KS, as shown in Table 1. The prevalence of AAC was higher among KSFs in comparison to non-SFs (i.e., $39.8 \%$ vs $20.2 \%, p<0.001$ ). Table 2 shows the results of the regression analyses set to assess the association between the presence of AAC and KS in models. There was a significant association between AAC and KSFs, (OR 2.618, 95\% CI 2.254-3.041, $p<0.001$ ), which was not found among non-SFs with the unadjusted model 1. In multivariable model 1 that was designed to adjust age and gender, it was observed that KSFs had higher AAC (OR 4.237, 95\% CI 3.529-5.087, $p<0.001$ ). In a similar vein, the relationship was also significant in multivariable model 2 which also adjusted hypertension, diabetes mellitus, drinking history, smoking history, FBG, UA, TG, Ca, and urine $\mathrm{pH}$ variables (OR 5.756, 95\% CI 4.616-7.177, $p<0.001$ ).

The stone composition of 1027 KSFs was investigated, which include $705 \mathrm{CaOx}, 222 \mathrm{CaP}, 55 \mathrm{UA}, 37$ struvite, and 8 others (i.e., 7 cystine and 1 drug-induced calculi). The baseline characteristics of KSFs based on a composition analysis are presented in Table 3. Table 4 illustrates the results of the regression analyses model which assessed the stone composition between AAC and non-AAC populations. In unadjusted analysis 2 , three compositions, namely $\mathrm{CaOx}$, $\mathrm{CaP}$ and Struvite were significantly associated with AAC (OR 1.476, 95\% CI 1.121-1.944, $p=0.006$; OR 0.667, 95\% CI $0.487-0.912, p=0.011$; OR $0.341,95 \%$ CI $0.148-0.785$, $p=0.011$, respectively), except for UA and others (OR $1.609,95 \%$ CI $0.934-2.772, p=0.087$; OR $0.214,95 \%$ CI $0.026-1.745, p=0.15$, respectively). However, only $\mathrm{CaOx}$ 
Table 1 General characteristics of the study, categorized according to kidney stone status
Table 2 The results of regression analysis models assessing AAC between KSFs and non-SFs

\begin{tabular}{llllr}
\hline & All $(n=4516)$ & KSFs $(n=1027)$ & non-SFs $(n=3489)$ & $P$ value \\
\hline Age, year & $49.0 \pm 11$ & $48.0 \pm 12.8$ & $49.2 \pm 10.4$ & 0.006 \\
Male $(\%)$ & $2749(60.9 \%)$ & $676(65.8 \%)$ & $2073(59.4 \%)$ & $<0.001$ \\
BMI kg/m ${ }^{2}$ a & $24.2 \pm 3.3$ & $24.0 \pm 3.5$ & $24.2 \pm 3.2$ & 0.235 \\
Hypertension $(\%)$ & $945(20.9 \%)$ & $156(15.2 \%)$ & $789(22.6 \%)$ & $<0.001$ \\
Diabetes mellitus $(\%)$ & $332(7.4 \%)$ & $71(6.9 \%)$ & $261(7.5 \%)$ & 0.54 \\
Drinking history $(\%)$ & $1908(42.2 \%)$ & $214(20.8 \%)$ & $1694(48.6 \%)$ & $<0.001$ \\
Smoking history $(\%)$ & $1428(31.6 \%)$ & $289(28.1 \%)$ & $1139(32.6 \%)$ & 0.006 \\
FBG mmol/L & $5.4 \pm 1.5$ & $5.3 \pm 1.2$ & $5.4 \pm 1.6$ & 0.024 \\
UA $\mu$ mol/L & $354 \pm 93$ & $363 \pm 96$ & $351 \pm 91$ & $<0.001$ \\
TG mmol/L & $1.73 \pm 1.34$ & $1.68 \pm 1.20$ & $1.74 \pm 1.38$ & 0.201 \\
TC mmol/L & $4.90 \pm 0.97$ & $4.51 \pm 0.91$ & $5.01 \pm 0.96$ & $<0.001$ \\
Ca mmol/L & $2.32 \pm 0.10$ & $2.29 \pm 0.12$ & $2.32 \pm 0.09$ & $<0.001$ \\
Urine PH & $6.01 \pm 0.65$ & $6.24 \pm 0.65$ & $5.95 \pm 0.63$ & $<0.001$ \\
AAC $(\%)$ & $1113(24.6 \%)$ & $409(39.8 \%)$ & $704(20.2 \%)$ & $<0.001$ \\
\hline Contin
\end{tabular}

Continuous variables were calculated by means \pm standard deviations and categorical variables were measured by counts (percentages)

$K S F s$ kidney stone formers, non-SFs non-stone formers, $B M I$ body mass index, $F B G$ fasting blood glucose, $U A$ uric acid, $T G$ serum triglyceride, $T C$ serum total cholesterol, $C a$ serum calcium, $A A C$ abdominal vascular calcifications

${ }^{a} \mathrm{BMI}$ was available in 4304 studied populations

${ }^{\mathrm{b}} \mathrm{Ca}$ was available in 4304 studied populations

\begin{tabular}{llll}
\hline & Unadjusted model 1 & Multivariable model 1 & Multivariable model 2 \\
\hline OR $(95 \% \mathrm{CI})$ & $2.618(2.254,3.041)$ & $4.237(3.529,5.087)$ & $5.756(4.616,7.177)$ \\
$P$ value & $<0.001$ & $<0.001$ & $<0.001$ \\
\hline
\end{tabular}

Multivariable model 1 adjusting age and gender. Multivariable model 2 adjusting for nine more parameters, namely hypertension, diabetes mellitus, drinking history, smoking history, FBG, UA, TG, Ca, and urine $\mathrm{pH}$ $C I$ confidence interval, $O R$ odds ratio had a significant association with AAC (OR 1.351, 95\% CI $1.002-1.822, p=0.048)$, after adjustment for age, hypertension, diabetes mellitus, drinking history, smoking history, and TG.

\section{Discussion}

Several interesting findings were disclosed in our research. First, multivariate analysis 2 confirmed that kidney stone disease is independently associated with AAC through a comparison of KSFs and non-SFs, despite the fact that potential confounders were noticed. Shavit L. et al. reported that KSFs with relapsing nephrolithiasis had a more severe AAC score than non-SFs $(p<0.001)$ [12]. Patients with intermediate or severe AAC was 1.9 times more likely to have KS than those without AAC (OR 1.9, $p=0.004$ ) [13]. The multivariable logistic regression suggests that the formation of recurrent KS was correlated with moderate or severe coronary artery calcification (CAC) rather than none or mild CAC (OR 1.80, 95\% CI 1.22-2.67) [14].

In what follows, our study is the first of its type to reveal the relationship between calcium oxalate stone and AAC after adjusting the vascular calcifications related confounding factors. Then, after controlling the KS-related confounding factors, our study still found a positive correlation between KS and AAC.

A further exploration also showed that the prevalence of KS in patients with AAC was significantly higher than non-SFs $(39.8 \%$ vs $20.2 \%, p<0.001)$. Karen L. Stern et al. claimed that AAC was more widespread among the KSFs [13]. Insofar, increasingly more medical literature referred to the concept of kidney calculi as a systemic disease. In a similar vein, many studies have demonstrated an association between kidney calculi and metabolic syndrome, hypertension, diabetes mellitus, or urine $\mathrm{pH}$, UA $[15,16]$. In fact, we found a higher prevalence of diabetes mellitus, hypertension, smoking history, and drinking history among 
Table 3 The baseline characteristics of KSFs with composition analysis

\begin{tabular}{llllr}
\hline & All $(n=1027)$ & AAC $(n=409)$ & non-AAC $(n=618)$ & $P$ value \\
\hline Age $>$ 30 year (\%) & $921(89.7)$ & $407(99.5)$ & $514(83.2)$ & $<0.001$ \\
Male (\%) & $676(65.8)$ & $284(69.4)$ & $392(63.4)$ & 0.051 \\
BMI $>28(\%)^{\mathrm{a}}$ & $99(12.1)$ & $45(13.4)$ & $54(11.2)$ & 0.331 \\
Hypertension (\%) & $156(15.2)$ & $110(26.9)$ & $46(7.4)$ & $<0.001$ \\
Diabetes mellitus (\%) & $71(6.9)$ & $54(13.2)$ & $17(2.8)$ & $<0.001$ \\
Drinking history (\%) & $214(20.8)$ & $106(25.9)$ & $108(17.5)$ & $<0.001$ \\
Smoking history (\%) & $289(28.1)$ & $142(34.7)$ & $147(23.8)$ & $<0.001$ \\
TG $>2.3$ mmol/L (\%) & $185(18.0)$ & $92(22.5)$ & $93(15.0)$ & 0.002 \\
TC $>6.2$ mmol/L (\%) & $36(3.5)$ & $19(4.6)$ & $17(2.8)$ & 0.106 \\
Size, mm & $17.0 \pm 8.0$ & $17.3 \pm 8.6$ & $16.7 \pm 7.5$ & 0.233 \\
Right kidney (\%) & $507(49.4)$ & $189(46.2)$ & $318(51.5)$ & 0.100 \\
CaOx (\%) & $705(68.6)$ & $301(73.6)$ & $404(65.4)$ & 0.005 \\
CaP $(\%)$ & $222(21.6)$ & $72(17.6)$ & $150(24.3)$ & 0.011 \\
UA $(\%)$ & $28(6.8)$ & $27(4.4)$ & 0.084 \\
Struvite (\%) & $55(5.4)$ & $7(1.7)$ & $30(4.9)$ & 0.008 \\
Others (\%) & $37(3.6)$ & $1(0.2)$ & $7(1.1)$ & 0.155 \\
\hline
\end{tabular}

Populations with kidney stones are divided into two groups based on the presence and absence of AAC to evaluate the relationship between AAC and stone composition

Continuous variables were calculated by means \pm standard deviations and categorical variables were measured by counts (percentages)

$A A C$ abdominal vascular calcifications, $\mathrm{CaOx}$ calcium oxalate calculi, $\mathrm{CaP}$ carbapatite, $U A$ urate stone, $B M I$ body mass index, $T G$ serum triglyceride, $T C$ serum total cholesterol

${ }^{a} \mathrm{BMI}$ was available in 818 studied populations

Table 4 The results of regression analysis models assessing stone composition between AAC and non-AAC

\begin{tabular}{|c|c|c|c|c|c|}
\hline & $\mathrm{CaOx}$ & $\mathrm{CaP}$ & UA & Struvite & Others \\
\hline \multicolumn{6}{|c|}{ Unadjusted model 2} \\
\hline OR (95\%CI) & $1.476(1.121,1.944)$ & $0.667(0.487,0.912)$ & $1.609(0.934,2.772)$ & $0.341(0.148,0.785)$ & $0.214(0.026,1.745)$ \\
\hline$P$ value & 0.006 & 0.011 & 0.087 & 0.011 & 0.15 \\
\hline \multicolumn{6}{|c|}{ Multivariable model 3} \\
\hline OR $(95 \% \mathrm{CI})$ & $1.351(1.002,1.822)$ & $0.732(0.522,1.025)$ & $1.477(0.809,2.696)$ & $0.447(0.186,1.076)$ & $0.180(0.017,1.933)$ \\
\hline$P$ value & 0.048 & 0.07 & 0.204 & 0.072 & 0.157 \\
\hline
\end{tabular}

Multivariable model 3 adjusting age, hypertension, diabetes mellitus, drinking history, smoking history, and TG

$\mathrm{CaOx}$ calcium oxalate calculi, $\mathrm{CaP}$ carbapatite, $\mathrm{UA}$ urate stone, $\mathrm{CI}$ confidence interval, $\mathrm{OR}$ odds ratio

non-SFs, whereas the prevalence of FBG, UA, or TG was similar among KSFs and non-SFs.

We discovered a higher prevalence of obesity, hypertension, diabetes mellitus, drinking history, smoking history, hyperlipidemia and hypercholesterolemia in patients with $\mathrm{AAC}$, if compared with those without AAC. In the unadjusted model 2, we analyzed the relationship between the components of $\mathrm{KS}$ and $\mathrm{AAC}$, and found that patients with $\mathrm{AAC}$ was 1.48 times more likely to have $\mathrm{CaOx}$-composed stones than those without $\mathrm{AAC}(\mathrm{OR}=1.476, p=0.006)$, whereas patients with AAC were less likely to have CaPand struvite-composed stones than those without AAC $(\mathrm{OR}=0.667 p=0.011 ; \mathrm{OR}=0.341 p=0.011)$. Multivariate analyses model 3 confirmed that AAC is independently associated with $\mathrm{CaOx}(\mathrm{OR}=1.351,95 \% \mathrm{CI} 1.002-1.822)$. Pietro Manuel Ferraro et al. have detected an association between AAC and CaP [17]. In this study, they used an alternative model that suggests KS components are comparable, just as protein, sugar, and fat can be easily compared based on energy calculation. However, this is not in conformity with the normal situation. Stone composition is not like protein, fat or sugar. KS components are usually a mixture. In most cases, the prominent composition of a urinary stone is $\mathrm{CaOx}$, accounting for about $50-80 \%$ of the total, followed by CaP and UA [18-20]. Patel et al. revealed that calcium phosphate is associated with AAC $(p=0.016)$, however, they did not probe the correlation between the two parameters [8]. 
Taguchi et al. disclosed that the production of M1 macrophages was induced by an oxalate-inducing diet [21]. Liu et al. reported that the formation of atherosclerosis and insulin-resistance were accompanied by the appearance and increase of M1 macrophage [22]. In Ketha et al. study, a blood electrolyte test of patients with urolithiasis has illustrated that serum calcium and phosphate ion concentration were higher in SFs [23]. Meanwhile, the increased calcium ion concentration activates the runt-related transcription factor, thereby transforming smooth muscle cells into osteoblast-like cells; then, these osteoblast-like cells facilitates the formation of the bone morphogenic proteins and osteopontin, thus leading to vascular calcification to some extent [24]. The expression of osteopontin and monocyte chemoattractant protein-1 appeared in different types of cells with the increase of both free oxalate ions and $\mathrm{CaOx}$ crystal [25, 26]. Kleinman et al. reported that osteopontin was involved in the defense of endogeny against crystal formation, which was detected in both SFs and animals with urolith [27]. Constantly elevated osteopontin accelerates plaque progression, which may play a part in prognostic biomarker [28]. Osteopontin promotes atherosclerosis and inhibits vascular calcification; osteopontin insufficiency in animal models attenuates atherosclerosis [29]. Oxalate itself induces the reactive oxygen species that promote inflammation and further conduce to systemic oxidation and vascular endothelial cells injury $[29,30]$. Moreover, recent research suggests that in ossification mechanism, there is a significant relationship between the active participation of proteins (i.e., osteopontin, bone sialoprotein, and bone morphogenetic protein 2) and transcription factors (i.e., core-binding factor $\alpha$ and runt-related transcription factor 2), which is also involved in the early phases of kidney stone formation and arterial calcification [31-35].

Furthermore, a new mechanism for the formation of kidney-mineral nanoparticles has been found in calcified blood vessels and kidney [36, 37]. Wong et al. have implied that precursors of calcification and renal stones may represent the nanoparticles in humans [36]. Both KS and aortic calcification were regarded as ectopic calcification, whose occurrence and progress may have a common underlying mechanism [38-40]. Letavernier et al. revealed that pyrophosphate deficiency might contribute to the development of vascular calcifications in KS formers [44]. The formation of Randalls plaques of calcium phosphate was taking place in basement membranes and the interstitium [41]. This course is analogous to bone formation as well as the process of coronary artery calcification [42].

Some limitations must be taken into account when interpreting the findings of the study. The composition of stones cannot be quantified, so the study could only reveal the main components of stones. Beyond that, since this is a retrospective study, data collection might have been influenced by some unknown confounding factors. For instance, a participant diagnosed with KS may have changed the previous unhealthy lifestyle and exercised more, which is likely to change the profile of confounders that influence the occurrence and development of AAC. It is also true that the accurate time of AAC and KS formation could not be evaluated, as this is a cross-sectional study. Hence, it is necessary to carry out longitudinal studies to understand this relationship in a more comprehensive manner. Moreover, patients with chronic diseases like hypertension and diabetes usually take drugs for a long time, which might also affect the formation kidney stones and $\mathrm{AAC}$

In conclusion, this study blazed the trail to investigate the correlation between calcium oxalate stone and AAC after an adjustment of confounding factors. The analyses show that $\mathrm{KS}$ and AAC are closely associated. Patients with AAC are more likely to have kidney stones. However, whether aortic calcification can predict KS needs further exploration. In a similar vein, the specific pathophysiological mechanisms of KS and aortic calcification need to be further clarified.

Acknowledgements The work is supported by The National Natural Science Fund of China (81770703, 81970602); Project of Science and Technology Department of Sichuan Province (2021YFS0116); 1.3.5 project for disciplines of excellence, West China Hospital, Sichuan University (ZYJC18015); Project of Guangzhou Medical University (HX-H1701002).

Author contributions BL: project development, data collection and analysis, manuscript writing; YT: project development, data management, manuscript editing; LZ, YL: project development, data analysis; XJ: data management, manuscript; HL: manuscript editing; YH: protocol, data collection, manuscript editing; $\mathrm{KW}$ : project development, data management, manuscript editing.

Funding The work is supported by The National Natural Science Fund of China (81770703, 81970602); Project of Science and Technology Department of Sichuan Province (2021YFS0116); 1.3.5 project for disciplines of excellence, West China Hospital, Sichuan University (ZYJC18015); Project of Guangzhou Medical University (HX-H1701002).

Availability of data and materials All original research materials are kept by corresponding author.

Code availability Not applicable.

\section{Declarations}

Conflict of interest The authors have no conflicts of interest to declare that are relevant to the content of this article.

Ethics approval The study protocol was approved by the Biomedical Ethics Committee at West China Hospital, Sichuan University (No. 2015-202).

Consent to participate No informed consent was required. Data concerning human patients were collected retrospectively. 
Consent for publication All authors read and approved the final manuscript and agree to its publication.

Open Access This article is licensed under a Creative Commons Attribution 4.0 International License, which permits use, sharing, adaptation, distribution and reproduction in any medium or format, as long as you give appropriate credit to the original author(s) and the source, provide a link to the Creative Commons licence, and indicate if changes were made. The images or other third party material in this article are included in the article's Creative Commons licence, unless indicated otherwise in a credit line to the material. If material is not included in the article's Creative Commons licence and your intended use is not permitted by statutory regulation or exceeds the permitted use, you will need to obtain permission directly from the copyright holder. To view a copy of this licence, visit http://creativecommons.org/licenses/by/4.0/.

\section{References}

1. Strohmaier W (2000) Course of calcium stone disease without treatment. What can we expect? Eur Urol 37(3):339-344. https:// doi.org/10.1159/000052367

2. Scales CD Jr, Smith AC, Hanley JM, Saigal CS (2012) Prevalence of kidney stones in the United States. Eur Urol 62(1):160-165. https://doi.org/10.1016/j.eururo.2012.03.052

3. Fwu CW, Eggers PW, Kimmel PL, Kusek JW, Kirkali Z (2013) Emergency department visits, use of imaging, and drugs for urolithiasis have increased in the United States. Kidney Int 83(3):479-486. https://doi.org/10.1038/ki.2012.419

4. Assimos D, Krambeck A, Miller NL, Monga M, Murad MH, Nelson CP, Pace KT, Pais VM Jr, Pearle MS, Preminger GM, Razvi H, Shah O, Matlaga BR (2016) Surgical management of stones: american urological association/endourological society guideline. PART I J Urol 196(4):1153-1160. https://doi.org/10.1016/j.juro. 2016.05.090

5. Türk C, Petř́ík A, Sarica K, Seitz C, Skolarikos A, Straub M, Knoll $\mathrm{T}$ (2016) EAU guidelines on diagnosis and conservative management of urolithiasis. Eur Urol 69(3):468-474. https://doi.org/10. 1016/j.eururo.2015.07.040

6. Ferraro PM, Taylor EN, Eisner BH, Gambaro G, Rimm EB, Mukamal KJ, Curhan GC (2013) History of kidney stones and the risk of coronary heart disease. JAMA 310(4):408-415. https:// doi.org/10.1001/jama.2013.8780

7. Davila JA, Johnson CD, Behrenbeck TR, Hoskin TL, Harmsen WS (2006) Assessment of cardiovascular risk status at CT colonography. Radiology 240(1):110-115. https://doi.org/10.1148/ radiol.2401050948

8. Skolarikos A, Straub M, Knoll T, Sarica K, Seitz C, Petř́k A, Türk C (2015) Metabolic evaluation and recurrence prevention for urinary stone patients: EAU guidelines. Eur Urol 67(4):750-763. https://doi.org/10.1016/j.eururo.2014.10.029

9. Patel ND, Ward RD, Calle J, Remer EM, Monga M (2017) Vascular disease and kidney stones: abdominal aortic calcifications are associated with low urine $\mathrm{pH}$ and hypocitraturia. J Endourol 31(9):956-961. https://doi.org/10.1089/end.2017.0350

10. Romero V, Akpinar H, Assimos DG (2010) Kidney stones: a global picture of prevalence, incidence, and associated risk factors. Rev Urol 12(2-3):e86-96

11. Herrmann J, Babic M, Tölle M, van der Giet M, Schuchardt M (2020) Research models for studying vascular calcification. Int J Mol Sci. https://doi.org/10.3390/ijms21062204

12. Shavit L, Girfoglio D, Vijay V, Goldsmith D, Ferraro PM, Moochhala SH, Unwin R (2015) Vascular calcification and bone mineral density in recurrent kidney stone formers. Clin J Am Soc Nephrol 10(2):278-285. https://doi.org/10.2215/CJN.06030614

13. Stern KL, Ward RD, Li J, Remer EM, Stoller ML, Monga M (2019) Nonrenal systemic arterial calcification predicts the formation of kidney stones. J Endourol 33(12):1032-1034. https://doi. org/10.1089/end.2019.0243

14. Hsi RS, Spieker AJ, Stoller ML, Jacobs DR Jr, Reiner AP, McClelland RL, Kahn AJ, Chi T, Szklo M, Sorensen MD (2016) Coronary artery calcium score and association with recurrent nephrolithiasis: the multi-ethnic study of atherosclerosis. J Urol 195(4 Pt 1):971-976. https://doi.org/10.1016/j.juro.2015.10.001

15. Menezes CJ, Worcester EM, Coe FL, Asplin J, Bergsland KJ, Ko B (2019) Mechanisms for falling urine $\mathrm{pH}$ with age in stone formers. Am J Physiol Renal Physiol 317(7):F65-f72. https:// doi.org/10.1152/ajprenal.00066.2019

16. Ferraro PM, Curhan GC (2017) Serum uric acid and risk of kidney stones. Am J Kidney Dis 70(2):158-159. https://doi.org/ 10.1053/j.ajkd.2017.05.004

17. Ferraro PM, Marano R, Primiano A, Gervasoni J, Bargagli M, Rovere G, Bassi PF, Gambaro G (2019) Stone composition and vascular calcifications in patients with nephrolithiasis. J Nephrol 32(4):589-594. https://doi.org/10.1007/s40620-019-00619-w

18. Sun X, Shen L, Cong X, Zhu H, He L, Lu J (2011) Infrared spectroscopic analysis of 5,248 urinary stones from Chinese patients presenting with the first stone episode. Urol Res 39(5):339-343. https://doi.org/10.1007/s00240-011-0362-1

19. Lee MC, Bariol SV (2013) Changes in upper urinary tract stone composition in Australia over the past 30 years. BJU Int 112(Suppl 2):65-68. https://doi.org/10.1111/bju.12383

20. Knoll T, Schubert AB, Fahlenkamp D, Leusmann DB, WendtNordahl G, Schubert G (2011) Urolithiasis through the ages: data on more than 200,000 urinary stone analyses. J Urol 185(4):1304-1311. https://doi.org/10.1016/j.juro.2010.11.073

21. Taguchi K, Okada A, Hamamoto S, Unno R, Moritoki Y, Ando R, Mizuno K, Tozawa K, Kohri K, Yasui T (2016) M1/M2-macrophage phenotypes regulate renal calcium oxalate crystal development. Sci Rep 6:35167. https://doi.org/10.1038/srep3 5167

22. Liu YC, Zou XB, Chai YF, Yao YM (2014) Macrophage polarization in inflammatory diseases. Int J Biol Sci 10(5):520-529. https://doi.org/10.7150/ijbs.8879

23. Ketha H, Singh RJ, Grebe SK, Bergstralh EJ, Rule AD, Lieske JC, Kumar R (2015) Altered calcium and vitamin D homeostasis in first-time calcium kidney stone-formers. PLoS ONE 10(9):e0137350. https://doi.org/10.1371/journal.pone.0137350

24. Lu KC, Wu CC, Yen JF, Liu WC (2014) Vascular calcification and renal bone disorders. Sci World J 2014:637065. https://doi.org/10. 1155/2014/637065

25. Evan AP, Bledsoe SB, Smith SB, Bushinsky DA (2004) Calcium oxalate crystal localization and osteopontin immunostaining in genetic hypercalciuric stone-forming rats. Kidney Int 65(1):154161. https://doi.org/10.1111/j.1523-1755.2004.00396.x

26. Umekawa T, Chegini N, Khan SR (2002) Oxalate ions and calcium oxalate crystals stimulate MCP-1 expression by renal epithelial cells. Kidney Int 61(1):105-112. https://doi.org/10.1046/j. 1523-1755.2002.00106.x

27. Kleinman JG, Wesson JA, Hughes J (2004) Osteopontin and calcium stone formation. Nephron Physiol 98(2):p43-47. https://doi. org/10.1159/000080263

28. Mazzone A, Parri MS, Giannessi D, Ravani M, Vaghetti M, Altieri P, Casalino L, Maltinti M, Balbi M, Barsotti A, Berti S (2011) Osteopontin plasma levels and accelerated atherosclerosis in patients with CAD undergoing PCI: a prospective clinical study. Coron Artery Dis 22(3):179-187. https://doi.org/10.1097/MCA. 0b013e3283441d0b 
29. Matsui Y, Rittling SR, Okamoto H, Inobe M, Jia N, Shimizu T, Akino M, Sugawara T, Morimoto J, Kimura C, Kon S, Denhardt D, Kitabatake A, Uede T (2003) Osteopontin deficiency attenuates atherosclerosis in female apolipoprotein E-deficient mice. Arterioscler Thromb Vasc Biol 23(6):1029-1034. https://doi.org/10. 1161/01.Atv.0000074878.29805.D0

30. Asokan D, Kalaiselvi P, Varalakshmi P (2004) Modulatory effect of the $23-\mathrm{kD}$ calcium oxalate monohydrate binding protein on calcium oxalate stone formation during oxalate stress. Nephron Physiol 97(1):p23-30. https://doi.org/10.1159/000077599

31. Yiu AJ, Callaghan D, Sultana R, Bandyopadhyay BC (2015) Vascular calcification and stone disease: a new look towards the mechanism. J Cardiovasc Dev Dis 2(3):141-164. https://doi.org/ $10.3390 /$ jcdd2030141

32. Khan SR, Canales BK (2015) Unified theory on the pathogenesis of Randall's plaques and plugs. Urolithiasis 43(1):S109-S123. https://doi.org/10.1007/s00240-014-0705-9

33. Gambaro G, Fabris A, Abaterusso C, Cosaro A, Ceol M, Mezzabotta F, Torregrossa R, Tiralongo E, Del Prete D, D'Angelo A, Anglani F (2008) Pathogenesis of nephrolithiasis: recent insight from cell biology and renal pathology. Clin Cases Miner Bone Metab 5(2):107-109

34. Kugimiya F, Kawaguchi H, Kamekura S, Chikuda H, Ohba S, Yano F, Ogata N, Katagiri T, Harada Y, Azuma Y, Nakamura K, Chung UI (2005) Involvement of endogenous bone morphogenetic protein (BMP) 2 and BMP6 in bone formation. J Biol Chem 280(42):35704-35712. https://doi.org/10.1074/jbc.M505166200

35. Komori $\mathrm{T}$ (2019) Regulation of proliferation, differentiation and functions of osteoblasts by Runx2. Int J Mol Sci. https://doi.org/ 10.3390/ijms20071694

36. Wong TY, Wu CY, Martel J, Lin CW, Hsu FY, Ojcius DM, Lin PY, Young JD (2015) Detection and characterization of mineralo-organic nanoparticles in human kidneys. Sci Rep 5:15272. https://doi.org/10.1038/srep15272

37. Martel J, Wu CY, Young JD (2016) Translocation of mineraloorganic nanoparticles from blood to urine: a new mechanism for the formation of kidney stones? Nanomedicine-UK 11(18):2399 2404. https://doi.org/10.2217/nnm-2016-0246

38. Letavernier E, Bouderlique E, Zaworski J, Martin L, Daudon M (2019) Pseudoxanthoma elasticum, kidney stones and pyrophosphate: from a rare disease to urolithiasis and vascular calcifications. Int J Mol Sci. Doi: https://doi.org/10.3390/ijms20246353

39. Barrett H, McElduff A (2010) Vitamin D and pregnancy: an old problem revisited. Best Pract Res Clin Endocrinol Metab 24(4):527-539. https://doi.org/10.1016/j.beem.2010.05.010

40. Khan SR, Rodriguez DE, Gower LB, Monga M (2012) Association of Randall plaque with collagen fibers and membrane vesicles. J Urol 187(3):1094-1100. https://doi.org/10.1016/j.juro. 2011.10.125

41. Taylor ER, Stoller ML (2015) Vascular theory of the formation of Randall plaques. Urolithiasis 43(Suppl 1):41-45. https://doi.org/ 10.1007/s00240-014-0718-4

42. Evan A, Lingeman J, Coe FL, Worcester E (2006) Randall's plaque: pathogenesis and role in calcium oxalate nephrolithiasis. Kidney Int 69(8):1313-1318. https://doi.org/10.1038/sj.ki.50002 38

Publisher's Note Springer Nature remains neutral with regard to jurisdictional claims in published maps and institutional affiliations. 